\title{
Substoichiometric Zirconia Thin Films Prepared by Reactive Sputtering of Metallic Zirconium Using a Direct Current Ion Beam Source
}

\author{
Thomas Götsch ${ }^{\mathrm{a}}$, Benedict Neumann ${ }^{\mathrm{a}}$, Bernhard Klötzer ${ }^{\mathrm{a}}$, Simon Penner ${ }^{\mathrm{a}, *}$ \\ ${ }^{a}$ Department of Physical Chemistry, Universität Innsbruck, A-6020 Innsbruck, Austria
}

\begin{abstract}
An ultra-high-vacuum-compatible direct current ion beam sputter source is used to deposit strongly defective zirconium dioxide thin films by operation in high vacuum with different oxygen and hydrogen partial pressures. It is shown that the target drain current can be used as a quantity to measure the deposition rate and the film thickness (via integration over time). The latter has a linear relation to the integrated drain current, enabling the simple prediction of the thicknesses after calibration, enabling a large range of possible thicknesses (from small sub-monolayer islands to more than $50 \mathrm{~nm}$ ). Furthermore, the defective nature of the films is shown when sputter-depositing onto copper and silicon substrates in different low oxygen (and hydrogen) pressures. When sputtering in hydrogen, traces of metallic Zr appear, which are much more pronounced for the deposition on $\mathrm{Si}$, owing to a possible reactive sputtering mechanism that involves a reaction with oxygen that is adsorbed on the substrate. In the end, we show calculations that demonstrate that, with simple modifications, multiple sputter source configurations for different purposes are possible, leading to different deposition rates.
\end{abstract}

Keywords: sputtering, zirconium, $\mathrm{ZrO}_{2}$, XPS, thin films

\section{Introduction}

Zirconia $\left(\mathrm{ZrO}_{2}\right)$ is an industrially important material. Its uses comprise a wide selection of fields, including catalysis, [1] high- $k$ gate materials in semiconductors, [2-5] special cutting tools, [6] oxygen sensors, [7] as well as dental applications [8, 9] and coatings in nuclear reactors.[10] In many cases, (point) defects play a large role in determining the properties, as they can for instance stabilize the tetragonal polymorph.[11] Additionally, zirconia species that are doped with trivalent ions (especially yttria-stabilized zirconia) contain oxygen vacancies as well, and are highly relevant due to their high ionic conductivity at elevated temperatures.[12] This renders them ideal for applications such as solid oxide fuel cells (SOFCs)[13] or chemical sensors.[14] Additionally, like $\mathrm{ZrO}_{2}$, these materials exhibit a high hardness[15] and a high thermal

\footnotetext{
*Corresponding author: Simon Penner, Innrain 52c, A-6020 Innsbruck, Austria; Email, simon.penner@uibk.ac.at; Phone, $+4351250758003$

Preprint submitted to Surface Science

October 11, 2018
}

(C) 2018. This manuscript version is made available under the CC-BY-NC-ND 4.0 license

http://creativecommons.org/licenses/by-nc-nd/4.0/

The final version is available at https://doi.org/10.1016/j.susc.2018.10.015 
stability, making them perfect candidates for thermal barrier coatings, [16] as well as for optical devices such as switchable mirrors.[17]

For many of these applications, including inverse model catalysts, [18, 19] or ultra-thin/submonolayer films for surface science applications,[20-22] thin films are required, which often are prepared using sputtering techniques, especially with reactive sputtering, where the metallic material is brought to reaction during the deposition process itself. Reactive sputtering has multiple benefits as compared to employing an oxide target. Metallic targets, because of their high electric conductivity, allow the use of direct current (DC) power supplies instead of more expensive radio-frequency $(\mathrm{RF})$ generators (which are required for the usually insulating oxides). Moreover, it increases the flexibility as the metallic target can be used to deposit multiple different compounds - for example, metallic and oxidic thin films are possible (using pure $\mathrm{Ar}$ or an $\mathrm{Ar} / \mathrm{O}_{2}$ mixture, respectively), but by mixing carbon sources such as methane into the sputter gas, carbides can be prepared.[23-29] Similarly, using nitrogen leads to nitrides.[30, 31] Furthermore, reactive sputtering is not limited to metallic targets, but can be used to transform one compound into another.[32]

The most common usage of reactive sputtering with zirconium is related to exploiting the reaction of $\mathrm{Zr}$ and $\mathrm{O}_{2}$ to form $\mathrm{ZrO}_{2}$ thin films,[33-44] and particles.[45] The addition of $\mathrm{N}_{2} \mathrm{O}$ to this mixture influences the glass temperature of the resulting thin films, but can also result in the formation of oxynitride compounds.[46]

Reactive sputtering is not limited to pure $\mathrm{ZrO}_{2}$, but can also be used to deposit mixed oxides. For instance, the possibility to deposit yttria-stabilized zirconia (YSZ) films was demonstrated using metallic targets made out of Zr-Y alloys, [15, 47, 48] or by employing separate Zr and Y targets (and varying the target-to-substrate distances independently for both, leading to different compositions).[49] Zirconia-doped hafnia $\left(\mathrm{HfO}_{2}\right)$ films were likewise prepared by sputtering of $\mathrm{Zr}-\mathrm{Hf}$ alloys. [50] Additionally, $\mathrm{Cr}_{2-x} \mathrm{Zr}_{x} \mathrm{O}_{3}$ phases were deposited with a segmented Cr/Zr target.[51] Similarly, using a metallic Zr target, onto which a Ta ring was fixed, zirconium-tantalum oxides could be formed.[52]

In addition to oxides, other zirconium compounds have been prepared by reactive sputtering, such as zirconium nitride,[53] or zirconium carbonitride.[54] Instead of oxygen, nitrogen (nitride) or a mixture of butane and nitrogen (carbonitride) were mixed into the argon. Also, as mentioned above, the addition of methane results in the deposition of carbides.[29]

All these depositions, however, were carried out using magnetron sputter sources, which operate at relatively high pressures (around $1 \times 10^{-2} \mathrm{hPa}$ ) that are required to ignite and sustain the plasma, rendering them unsuitable for ultra-high-vacuum-based surface science studies without additional efforts such as dedicated, external chambers for the deposition. In this work, we demonstrate the possibility of using an ion-beam based sputter source, which can be used at significantly lower pressures (in the high $1 \times 10^{-5} \mathrm{hPa}$ to the low $1 \times 10^{-4} \mathrm{hPa}$ range) and which is compatible with ultra-high vacuum (UHV) systems, for reactive sputtering of a metallic zirconium target to form strongly reduced, defective oxidic thin films, with nominal thicknesses ranging from a few angstrom to more than $50 \mathrm{~nm}$ (thus covering the regimes of island growth and 
full coverage films). This was achieved using our self-built direct current ion beam sputter source,[55, 56] which has previously been shown to also work excellently for the non-reactive sputter-deposition of oxidic YSZ materials, [55, 57, 58] as well as with different oxides such as perovskites or pyrochlores.[59] Furthermore, our sputter source was adapted for UHV-based low-coverage depositions for STM studies by Lackner et al.,[60] who modified the geometry slightly, featuring two quasi-hemispherical grids in order to increase the ionization volume and to focus the Ar ions onto a spot on the target.

\section{Experimental}

\subsection{Thin Film Deposition}

For the deposition of the thin films, a modular high vacuum chamber (reaching base pressures in the low $1 \times 10^{-7} \mathrm{hPa}$ range) was used. This chamber was pumped using a turbomolecular pump and a small cryopump. The sputter-deposition was carried out in approximately $2 \times 10^{-4} \mathrm{hPa}$ of $\mathrm{Ar}$ mixed with different oxygen or hydrogen concentrations (between $0.6 \%$ and $2 \%$ ), corresponding to partial pressures in the range of $1.5 \times 10^{-6} \mathrm{hPa}$ to $3 \times 10^{-6} \mathrm{hPa}$ using a self-developed ion beam direct current sputter source.[55, 56] As the target, a $10 \mathrm{~mm} \times 10 \mathrm{~mm} \mathrm{Zr}$ foil $(d=125 \mu \mathrm{m})$ was used that was spot-welded to a Ta wire (with a diameter of $0.3 \mathrm{~mm}$ ). The target-to-substrate distance was kept at approximately $30 \mathrm{~mm}$ in order to prepare films with up to $60 \mathrm{~nm}$ thickness. At these distances, it is impossible to deposit the material onto a substrate and a quartz microbalance at the same time, which is why the deposition rate could not be determined using the latter. Instead, as explained later, the integrated drain current (measured at the target) was used to determine the thicknesses of the resulting thin films.

As substrates, $\mathrm{Cu}$ foils and $\mathrm{Si}(100)$ wafers were employed at room temperature and at $680 \mathrm{~K}$. To avoid transferring surface contaminations from the target to the thin films, the targets were pre-sputtered for multiple hours before starting the deposition onto the substrates. All gases used were of high purity (99.999\%).

The finite element calculations of the electric potential around the sputter source head were conducted for a $2 \mathrm{D}$ axisymmetric geometry in the stationary case using the COMSOL Multiphysics software package. Furthermore, this software was used to calculate the ion trajectories in the calculated electric fields (neglecting space charge effects).

\subsection{Characterization of the Thin Films}

X-ray photoelectron spectrometry was performed using a Thermo Scientific MultiLab 2000 spectrometer, with base pressures in the low $1 \times 10^{-10} \mathrm{hPa}$ range. This instrument was equipped with an Alpha 110 hemispherical sector analyzer, as well as a monochromated $\mathrm{Al} \mathrm{K}_{\alpha} \mathrm{X}$-ray source $(1486.6 \mathrm{eV})$. A flood gun, providing electrons with $6 \mathrm{eV}$, was utilized for charge neutralization, while an ion source was used for sputterdepth-profiling (with $\mathrm{Ar}^{+}$ions at $3 \mathrm{keV}$ ). The sputter rate during depth profiling was calibrated with an 
optical band pass filter, for which the thicknesses of the different layers could be calculated from the UV/VIS spectrum. At the surface, the charge-induced shifts were corrected for by setting the $\mathrm{C}-\mathrm{C}$ component of the $\mathrm{C} 1 \mathrm{~s}$ region (which is due to adventitious carbon) to a binding energy of $284.8 \mathrm{eV}$. Since, after the first sputtering phase, no carbon is present in the spectra, all subsequent spectra were shifted so that the $3 \mathrm{~d}_{5 / 2}$ component of the $\mathrm{Zr}(\mathrm{IV})$ oxidation state after the first sputtering phase was located at a binding energy of $182.6 \mathrm{eV} .[61,62]$ For the quantification of the XP spectra, the different escape depths of the regions were corrected for by means of the G-1 formula.[63] Furthermore, the sputter rates were calibrated using an optical band pass filter consisting of multiple well defined layers.

\section{Results}

\subsection{Operation and Calibration of the Sputter Source}

Figure 1a) shows a CAD drawing of the direct current ion beam sputter source used in this work, as described in [55]. The filament is mounted on small Ta hooks, which are electrically isolated from the shielding (at the top) by double-bored ceramic elements, except at one point, which is used to conduct the current to the filament (via the threaded rod seen on the right; the other end of the filament is connected to the ground (not shown)). This current is used to heat the filament, causing it to emit electrons, which are subsequently accelerated toward the conical grid, which is kept at $250 \mathrm{~V}$. Inside this grid, they ionize that fraction of the Ar atoms of the sputter gas, which become accelerated toward the target (kept at $-2 \mathrm{kV}$ ), causing the ablation of this target material. The target shown in this image can be a metal foil or, for instance, a ceramic pellet. A big advantage of this particular source is the unobstructed line of sight between the target and the substrate (with no grids in-between), as well as the large area that can be deposited upon.

An analysis of the electric potentials in the source head, calculated using a finite element method (FEM), is given in Figure 1b). The geometry shown in panel a) was approximated by a radially symmetrical version to speed up the computations and is represented by the black lines and curves. Thus, the grid is replaced by a series of co-axial circular wires (ignoring the vertical supports), and the helically coiled filament is substituted by a circular tube serving as an estimation. In the graphic, these elements are displayed as different circles (with black outlines). Similarly, the cross-sections of the target and the shielding are shown as black lines. The color scale denotes the potential, ranging from $-2 \mathrm{kV}$ (blue) to $250 \mathrm{~V}$ (red). Two isopotential curves are drawn that represent regions where the electrons have $16 \mathrm{eV}$ and $60 \mathrm{eV}$, respectively. The former corresponds to the minimal energy required for electron impact ionization of Ar, whereas the ionization cross section is maximized at the latter.[64-66] While the volume inside of which the ionization is possible is larger outside of the conical grid, these ions are not accelerated toward the target as the positive potential of the grid itself forms an efficient blockade. Thus, the Ar ions bombarding the target originate from 
a)
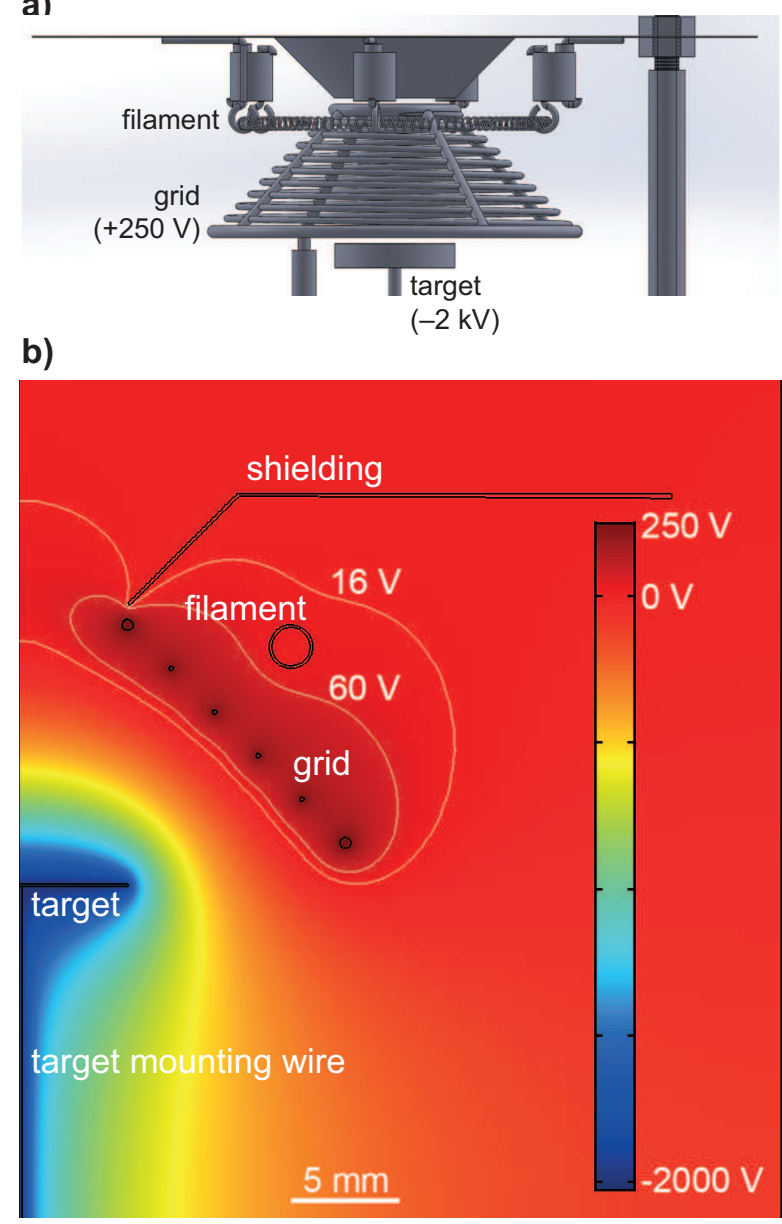

d)

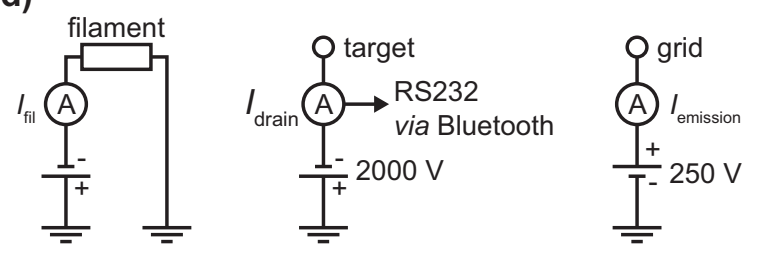

c)

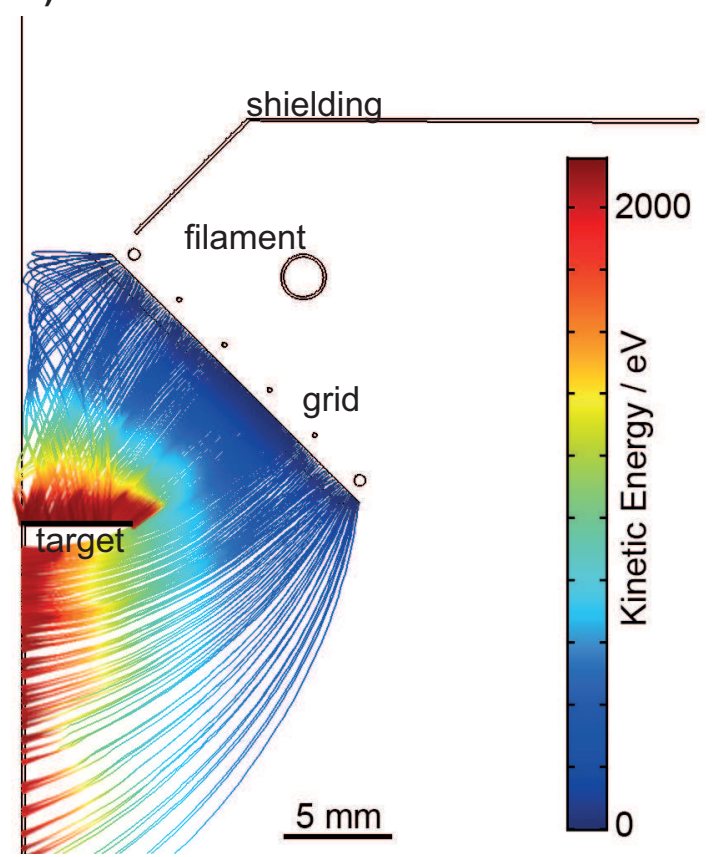

Figure 1: a) The geometry of our sputter source (adapted from Ref. [55]). b) Finite element simulation of the electric potentials at the sputter source head. For the sake of simplicity, the geometry of the source was approximated by a radially symmetric system. The iso-potential lines show the regions where the electrons have above 16 and $60 \mathrm{eV}$. c) The trajactories of Ar ${ }^{+}$ ions that are formed in the volume shown in b). d) Electric configuration of the source. To log the sputter current, an RS232-to-Bluetooth converter was employed.

a relatively small volume just inside of the grid, resulting in a relatively low deposition rate, which is desired for highly epitaxial growth. This ionization volume was increased by a modified version reported by Lackner et al. via the use of two grids that, however, are located between the target and the substrate,[60] blocking some of the sputtered material from being deposited onto the substrate. Furthermore, the sputtering of the backside of the target is minimized, which is important as this could lead to the coverage of insulating ceramic elements by a conducting layer.

This is confirmed by simulations of the ion trajectories for the $\mathrm{Ar}^{+}$particles that are formed in the volume where electrons have more than $60 \mathrm{eV}$. The results of these calculations are shown in Figure 1c). The color scale denotes the kinetic energy of the particles, with blue corresponding to $0 \mathrm{eV}$ and red representing $2 \mathrm{keV}$. 
Ions that crossed the left border in the image, which corresponds to the axis of rotational symmetry of this system, are reflected in the calculation to account for the symmetry. Due to the limited number of time steps for this simulation (running up to $1 \mu \mathrm{s}$ ), these reflections result in some artifacts of the particle traces close to the left border, which, however, do not affect the interpretation. In this computation, only those Ar ions formed within the conical grid (in the regions that are accessible to the electrons from the filament) are considered as those formed outside exhibit a low kinetic energy and subsequently are effectively caught by the shielding or the chamber walls and, thus, have no impact on the deposition process (these ions have no line of sight to the substrate, which is located just above the shielding). This image confirms that no sputtering of the backside of the metallic target occurs, with about $60 \%$ of the total formed Ar ions hitting the substrate-facing side of the target. At the current position of the target, some of the ions are accelerated towards the mounting wire. In practice, this isn't much of a problem since this wire is surrounded by an aluminium oxide ceramic tube. Hence, the impacts of these ions are not seen when measuring the drain current of the target. Furthermore, any sputtered $\mathrm{Al}_{2} \mathrm{O}_{3}$ from the ceramic cannot be deposited on any crucial parts such as the target itself or the substrate as no line of sight exists. The number of Ar ions hitting the mounting wire below the target could be reduced by moving the target further away from the grid, which is possible for metallic targets, but poses a problem for more insulating ones, where the radiative heating due to the proximity to the hot filament is required to improve the conductivity.[55] Also, moving the target downward would increase the target-to-substrate distance and thereby reduce the deposition rate significantly. The ions that hit the target in Figure1c) are distributed across the whole surface, leading to an exceptionally high target utilization, which is desirable for the deposition of thicker films as it increases the lifetime of the target. The top of the conical grid also effectively creates a potential barrier for Ar ions, preventing them from hitting the substrate and sputtering the surface of the growing thin film, which is a problem with the two-grid version used by Lackner et al.[60]

In Figure 1d), the electric configuration of the source is shown schematically. Usually, the filament current is adjusted so that the emission current, $I_{\text {emission, }}$, measured as the drain current of the grid, is in the range of $120 \mathrm{~mA}$. An amperemeter placed between the high voltage power supply and the target is used to measure the drain current at the target, which results from the neutralization of the Ar ions upon their impacts and acts as a measure for the sputter rate (since the sputter yield will remain constant for a given target and the ions hitting the insulating ceramic of the mounting wire do ot contribute to this current) and, by subsequent integration, for the amount of deposited material. Since the battery-powered amperemeter floats at a potential of $-2000 \mathrm{~V}$ with respect to the ground, the logging of this target drain current was performed by sending the serial RS232 signal that is provided by the amperemeter to a computer by means of a Bluetooth connection (with an HC-06 device, Guangzhou HC Information Technology).

An example recording of the drain current acquired this way can be seen in Figure 2. The black curve represents the current, and the red one its integration with respect to the time (right axis). After the high 


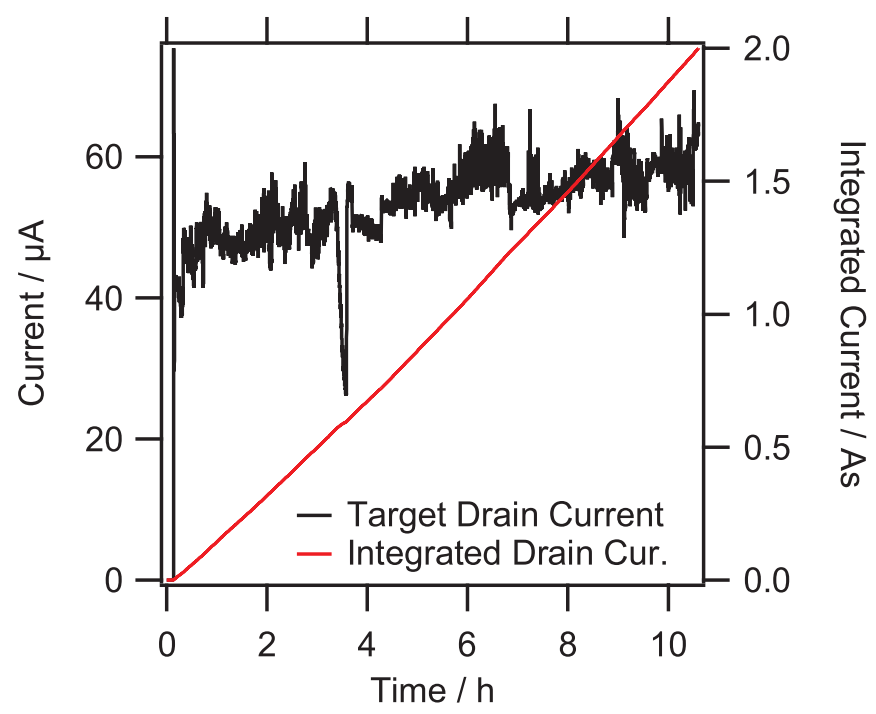

Figure 2: Recorded drain current at the target (black curve), as well as the integrated curve (red), which was used as a measure for the thickness of the films.

voltage is turned on a few minutes into the measurement, the current quickly stabilizes at approximately $50 \mu \mathrm{A}$ and remains in the region between 50 and $60 \mu \mathrm{A}$ throughout the whole experiment, which was a long-term deposition of a film that was measured to be about $55 \mathrm{~nm}$ thick (see below, the preparation was performed with $3 \times 10^{-6} \mathrm{hPa}$ of $\mathrm{O}_{2}$ added to $2 \times 10^{-4} \mathrm{hPa}$ of $\mathrm{Ar}$ ). The intermediate decrease of the current just below the $4 \mathrm{~h}$ mark was due to a small drop in the argon pressure. The drain current shown here is representative of the sputter rate - assuming that every particle impinging on the target surface is a singly charged $\mathrm{Ar}^{+}$ion and every ion is neutralized upon the $\mathrm{Ar}^{+}$impact, a drain current of $50 \mu \mathrm{A}$ corresponds to a particle current of $3.12 \times 10^{14} \mathrm{~s}^{-1}$. However, as demonstrated by Bogaerts and Gijbels for copper surfaces,[67] the Ar ion impact causes a significant secondary electron emission. For ion energies of $2 \mathrm{keV}$, they obtained a secondary electron yield of about 0.12 per impinging ion on a clean surface (albeit for glow discharges at higher pressures than used in the present work), which would mean that our method of recording the drain current overestimates the deposition rate. On dirty $\mathrm{Cu}$ surfaces, the secondary electron yield was shown to be higher due to effects from fast neutral Ar atoms,[67] which, however, is not expected to be relevant to this work as our pressures are lower and the surface of the target is automatically cleaned during the sputter-deposition process. Consequently, for a given ion energy, the electron emission is constant. Thus, with the assumptions of a constant sputter yield and a constant cross section for the emission of secondary electrons, this integrated sputter charge is proportional to the sputter rate. Consequently, integrating this drain current with respect to the time yields information about the thickness of the thin film.

The suitability of the integrated drain current for describing the film thicknesses was tested using XPS sputter-depth-profiling (with an Ar ion source of $3 \mathrm{keV}$ ). Several films were deposited for different amounts 
a)
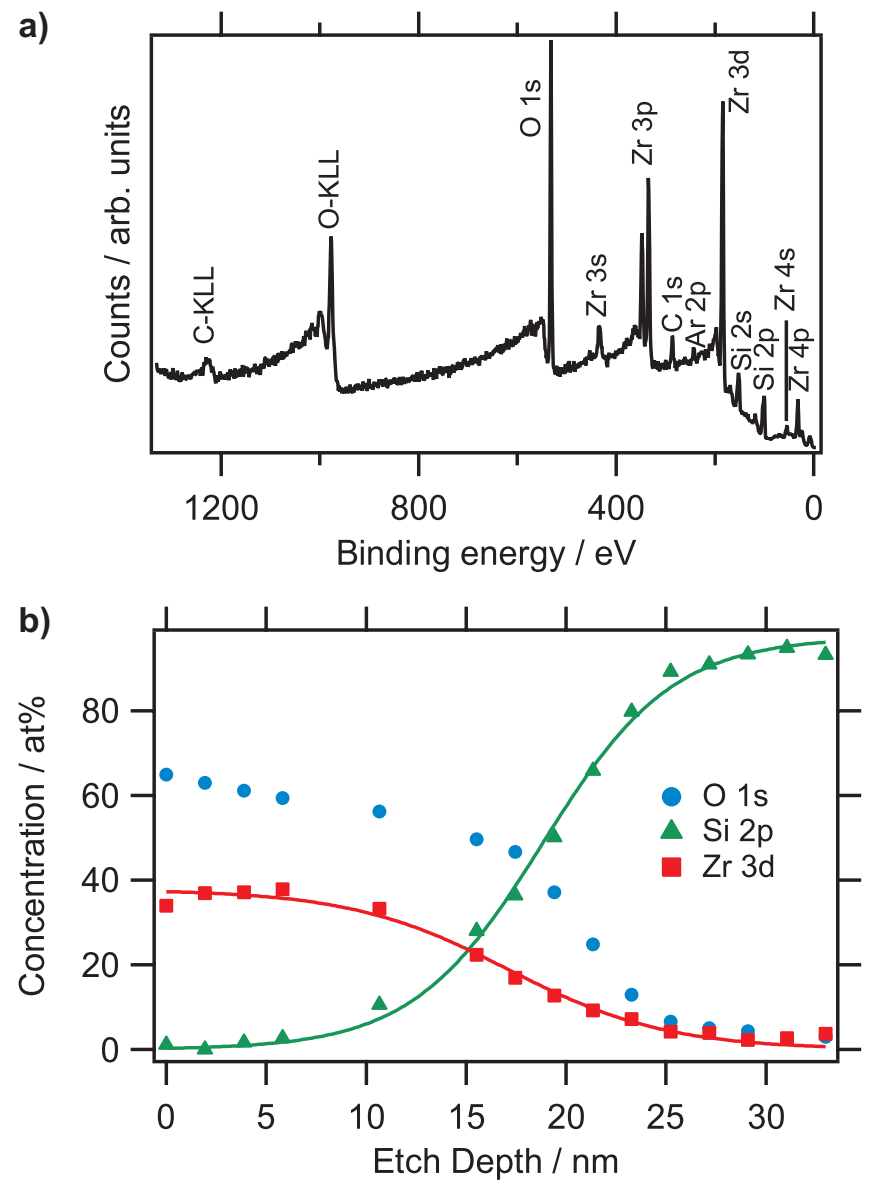

Figure 3: Exemplary a) XP survey spectrum (surface) and b) depth profile of a thin film prepared by reactive sputtering in an $\mathrm{Ar} / \mathrm{O}_{2}$ mixture (1.3\% oxygen). The solid curves are sigmoidal fits of the $\mathrm{Zr}$ and $\mathrm{Si}$ concentrations.

of time, with the integrated currents ranging from $0.1 \mathrm{As}$ to $2 \mathrm{As}$, and depth profiles were recorded subsequently. An example is given in Figure 3, showing the surface spectrum (panel a)) and the compositional depth profile (b) of a thin film that has been sputter-deposited until the transferred charge (time-integrated target drain current) reached $1 \mathrm{As}$. As seen in the survey spectrum in a), the film exhibits no contaminants apart from small amounts of adventitious carbon (that are removed in an initial cleaning step during the sputter depth profiling) and residual amounts of Ar, which result from the sputtering process. The Si signals stem from the underlying substrate as the film only has a nominal thickness of about $1.5 \mathrm{~nm}$. The red squares in Figure 3b denote the Zr concentration (determined using the Zr 3d region), while the blue circles represent oxygen (a result of the quantification of the O 1s peak), and the green triangles show the Si concentrations, based on the Si 2 p region. The oxygen content decreases slightly upon sputtering, which is due to the preferential sputtering of $\mathrm{O}$ due to its lower mass - an effect that has already been demonstrated in previous works. $[55,68]$ This and the fact that the surface of the Si wafer contains a very thin passivating 
$\mathrm{SiO}_{2}$ layer make it impossible to use the oxygen signal for the determination of the thin film thickness. However, the $\mathrm{Zr}$ and Si signals can be used instead. The concentration profiles as a function of the etching depth $\left(c\left(d_{\text {etch }}\right)\right)$ can be fitted by a sigmoidal function,

$$
c\left(d_{\text {etch }}\right)=c_{0}+\frac{c_{\max }}{1+\exp \left(\left(d_{\text {film }}-d_{\text {etch }}\right) / a\right)},
$$

where $c_{0}$ and $c_{\max }$ are the offset and the height of the profile, respectively. $d_{\text {film }}$ is the film thickness (corresponding to the inflection point of the curve) and $d_{\text {etch }}$ denotes the etching depth at each point. Since the inflection point can be measured for the $\mathrm{Zr}$ signal and for the substrate, one depth profile yields two thickness values, improving the statistics. In this case, the thickness can be estimated to be $16.4(2) \mathrm{nm}$ according to the $\mathrm{Zr} 3 \mathrm{~d}$ region and 19.0(2) $\mathrm{nm}$ when the Si signal is analyzed.

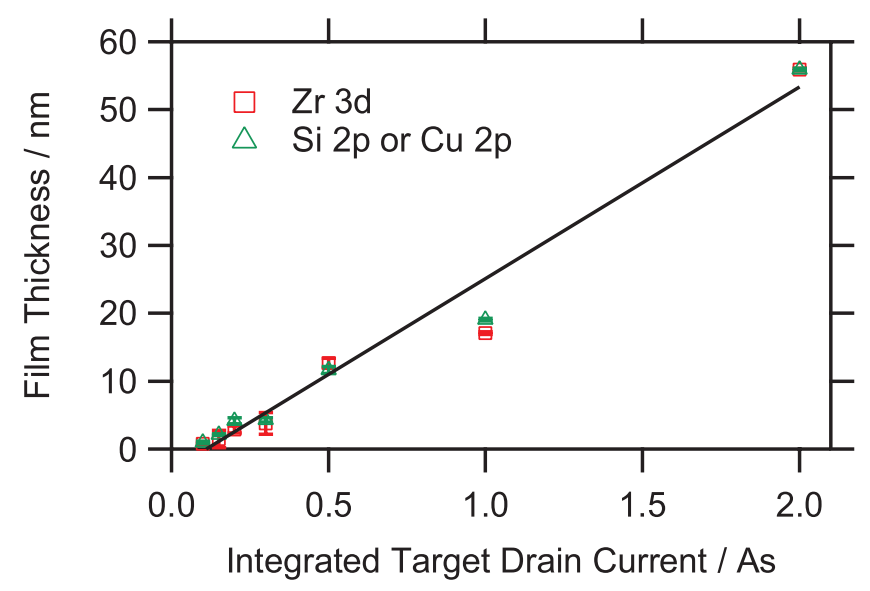

Figure 4: The Film thickness shows a linear behavior as a function of the integrated target drain current.

This process was repeated for multiple film thicknesses, and, as shown in Figure 4, the film thickness can be described adequately by a linear dependence on the integrated drain current. These data include the thicknesses obtained with the $\mathrm{Zr} 3 \mathrm{~d}$ region and with the substrate peaks $(\mathrm{Cu} 2 \mathrm{p}$ or $\mathrm{Si} 2 \mathrm{p}$, depending on which substrate was used, copper foil or a $\mathrm{Si}$ wafer). The slope of the fitted line reveals a deposition rate of $28.25(8) \mathrm{nm} \mathrm{A}^{-1} \mathrm{~s}^{-1}$. Also, with $-3.12(8) \mathrm{nm}$, the $y$ axis intersection is not only non-zero, but actually negative. This indicates that, at low deposited amounts, the films are not growing layer-by-layer (as assumed during the thickness analysis), but rather exhibit an island growth. This calibration can be used to get films of a desired thickness, removing the need for a quartz crystal microbalance.

\subsection{Deposition of Defective Zirconia Thin Films}

One advantage of ion-beam-based sputter sources, apart from their low deposition rates facilitating epitaxial growth, is that they are operated under high vacuum conditions. Thus, very low oxygen partial pressures are possible, leading to strongly substoichiometric thin films. The defectiveness of the resulting 


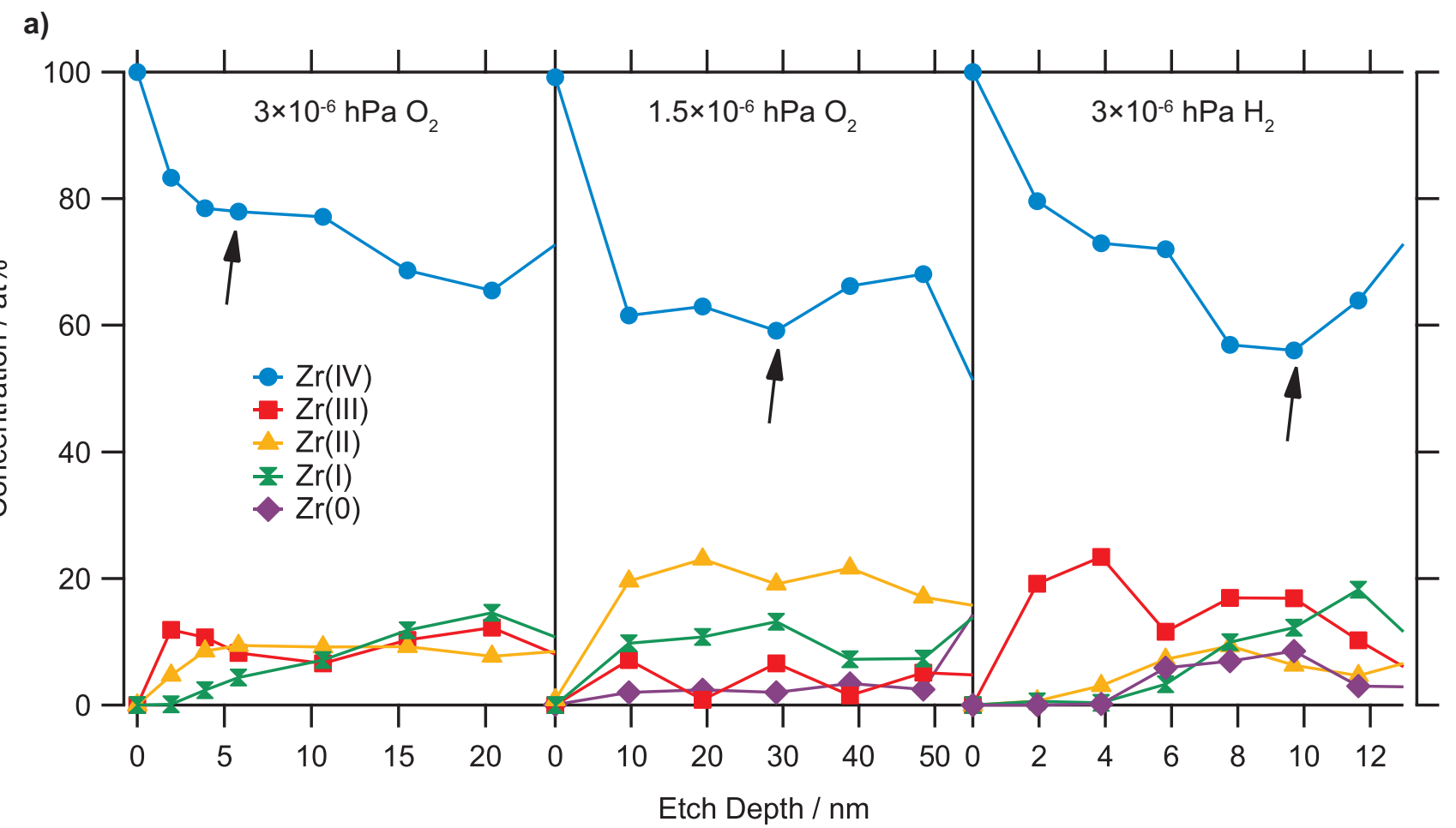

b)

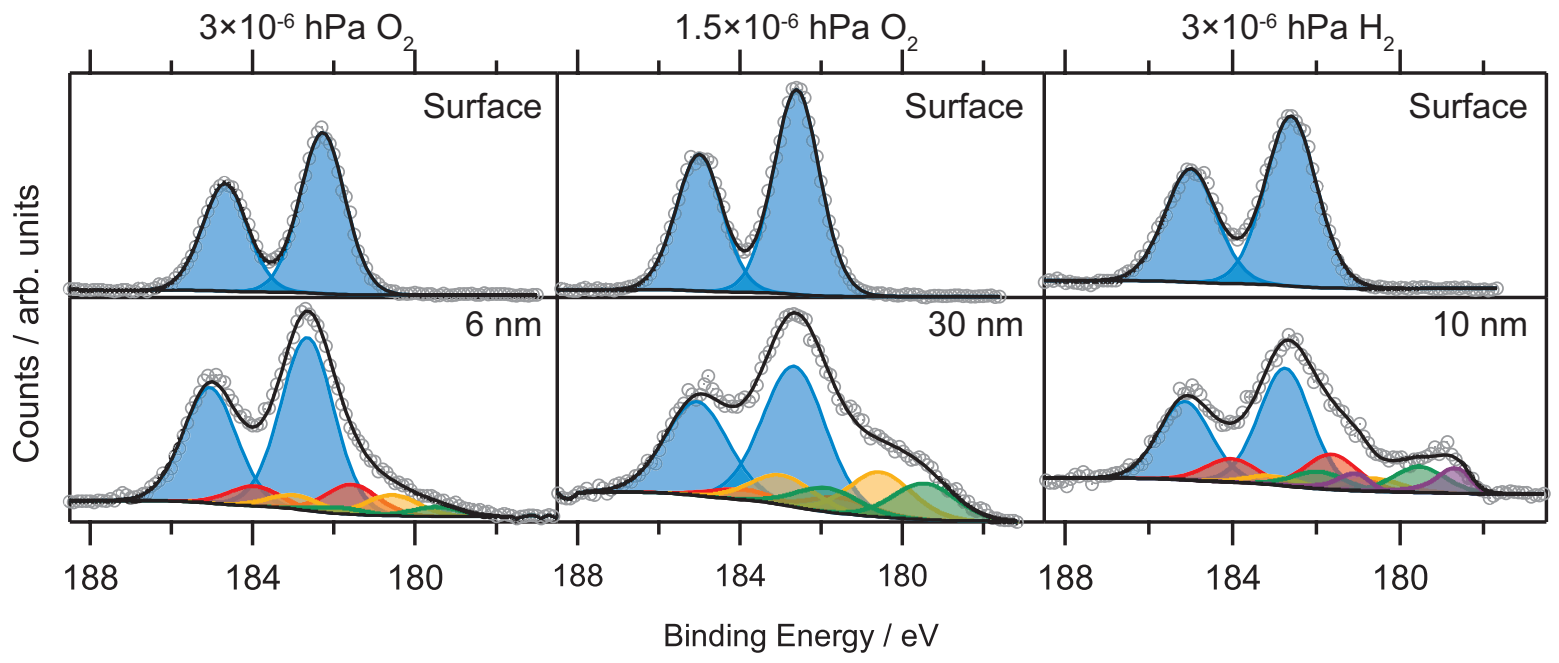

Figure 5: Depositions in different gas atmospheres on $\mathrm{Cu}$ substrates. a) Chemical state depth profiles for depositions in $2 \times 10^{-4} \mathrm{hPa} \mathrm{Ar}+3 \times 10^{-6} \mathrm{hPa} \mathrm{O}_{2}$ (left), $1.5 \times 10^{-6} \mathrm{hPa} \mathrm{O}_{2}$ (center) and $3 \times 10^{-6} \mathrm{hPa}$ of $\mathrm{H}_{2}$ (right). The axes show only the region before the inflection point as shown in Figure 3 because the fits are unreliable for low $\mathrm{Zr}$ concentrations. b) Exemplary XP spectra of the surface (top panels) and at the depths indicated by the arrows in a) show different suboxide configurations within the film. The color-coding in b) is the same as in a).

samples was investigated more closely by varying the oxygen partial pressures. In Figure 5, so-called chemical state depth profiles, which plot the concentrations of different oxidation states (obtained via peak fitting of the $\mathrm{Zr} 3 \mathrm{~d}$ region) as a function of the etching depth, are shown for films deposited on $\mathrm{Cu}$ foil substrates. The 
left panel was obtained for a film prepared using $3 \times 10^{-6} \mathrm{hPa}$ of oxygen in approximately $2 \times 10^{-4} \mathrm{hPa} \mathrm{Ar}$. The surface is fully oxidized, with only $\mathrm{Zr}(\mathrm{IV})$ states being present, whereas the amount of $\mathrm{Zr}$ (IV) decreases rapidly upon sputter-etching the specimen during the XPS investigations. As discussed before, this was also observed for films prepared using oxidic targets and is partially resulting from the preferential removal of oxygen from the lattice by Ar ions.[55, 59, 68] However, in these previous studies, the $\operatorname{Zr}(\mathrm{IV})$ concentration never dropped to values below $80 \%$. While preferential sputtering of oxygen plays a role here as well, the film itself must already possess a higher amount of suboxides in the first place in order to yield such low $\mathrm{Zr}(\mathrm{IV})$ concentrations. This is confirmed by the different behavior of the lower oxidation states. Close to the surface, $\operatorname{Zr}(\mathrm{III})$ is the most prominent of these states, whereas, in proximity to the substrate, $\mathrm{Zr}$ (I) is more abundant, which was never observed for fully oxidized systems. That the surface is fully oxidized is a result of the contact with air of these samples because $\mathrm{Zr}$ is prone to oxidation even at room temperature (and, in fact, is an excellent getter material for oxygen even in UHV conditions) - this is also observed for metallic Zr foils for instance that form a relatively thick passivating oxide layer. The left panels in Figure 5b) display examples of the XP spectra of this specimen. At the surface, the apparent peak splitting between the $3 \mathrm{~d}_{5 / 2}$ and $3 \mathrm{~d}_{3 / 2}$ components is well resolved and only $\mathrm{Zr}(\mathrm{IV})$ states, with the $3 \mathrm{~d}_{5 / 2}$ peak at $182.6 \mathrm{eV},[61,62]$ are present. At a depth of $6 \mathrm{~nm}$, the separation of the two main peaks is significantly weaker, suggesting an increased suboxide concentration, which is confirmed by the low-binding-energy tailing of the region, to which states ranging from $\mathrm{Zr}(\mathrm{I})$ to $\mathrm{Zr}$ (III) can be fitted. The $5 / 2$ component of $\mathrm{Zr}$ (III) is found at $181.5 \mathrm{eV}$, that of $\mathrm{Zr}(\mathrm{II})$ at $180.5 \mathrm{eV}$ and the maximum of the $\mathrm{Zr}(\mathrm{I}) 3 \mathrm{~d}_{5 / 2}$ signal is located at $179.4 \mathrm{eV}$. [61, 69]

The altered behavior from films deposited using oxidic targets is even more pronounced for lower oxygen concentrations: the data in the middle panel were recorded for a sample that was synthesized in $1.5 \times 10^{-6} \mathrm{hPa}$ oxygen, which is half the partial pressure used in the left panel. In this specimen, the $\mathrm{Zr}(\mathrm{IV})$ concentration drops even more rapidly to values of approximately $60 \%$. Even though the depth-profiling parameters were the same, i.e. the preferential sputtering of $\mathrm{O}$ from the lattice should result in the same loss of $\operatorname{Zr}(\mathrm{IV})$, this film is significantly more reduced, indicating the influence of the sputter gas on the defectiveness of the films. Additionally, throughout the whole film thickness, $\mathrm{Zr}$ (II) is the most prominent oxidation state, followed by $\operatorname{Zr}(\mathrm{I})$. This also shows in the XP spectra in b), where there is a distinct shoulder at the lower binding energy side at a depth of $30 \mathrm{~nm}$, hinting at an increased $\operatorname{Zr}$ (II) and $\operatorname{Zr}$ (I) concentration, which is confirmed in the peak fit model.

When the oxygen is replaced by hydrogen $\left(3 \times 10^{-6} \mathrm{hPa}\right)$, the degree of reduction is even higher. At a depth of about $8 \mathrm{~nm}$, the $\mathrm{Zr}(\mathrm{IV})$ concentration in Figure 5a) drops even below $60 \%$, which is accompanied by an increase in the amount of metallic Zr, which was not observed for the other experiments. In panel b), the large array of different states can be seen, with there being a very well separated peak just above $178 \mathrm{eV}$, which contains the $\operatorname{Zr}(0)$ and parts of the $\mathrm{Zr}(\mathrm{I})$ signals. Metallic zirconium was described using an asymmetric peak shape (with a high-binding-energy tailing) and its $5 / 2$ component is located at $178.5 \mathrm{eV}$.[61] 
That the film is still fully oxidized at the surface can be attributed to the high reactivity of Zr toward oxygen, as the same effect is also found for pure metallic Zr.

a)

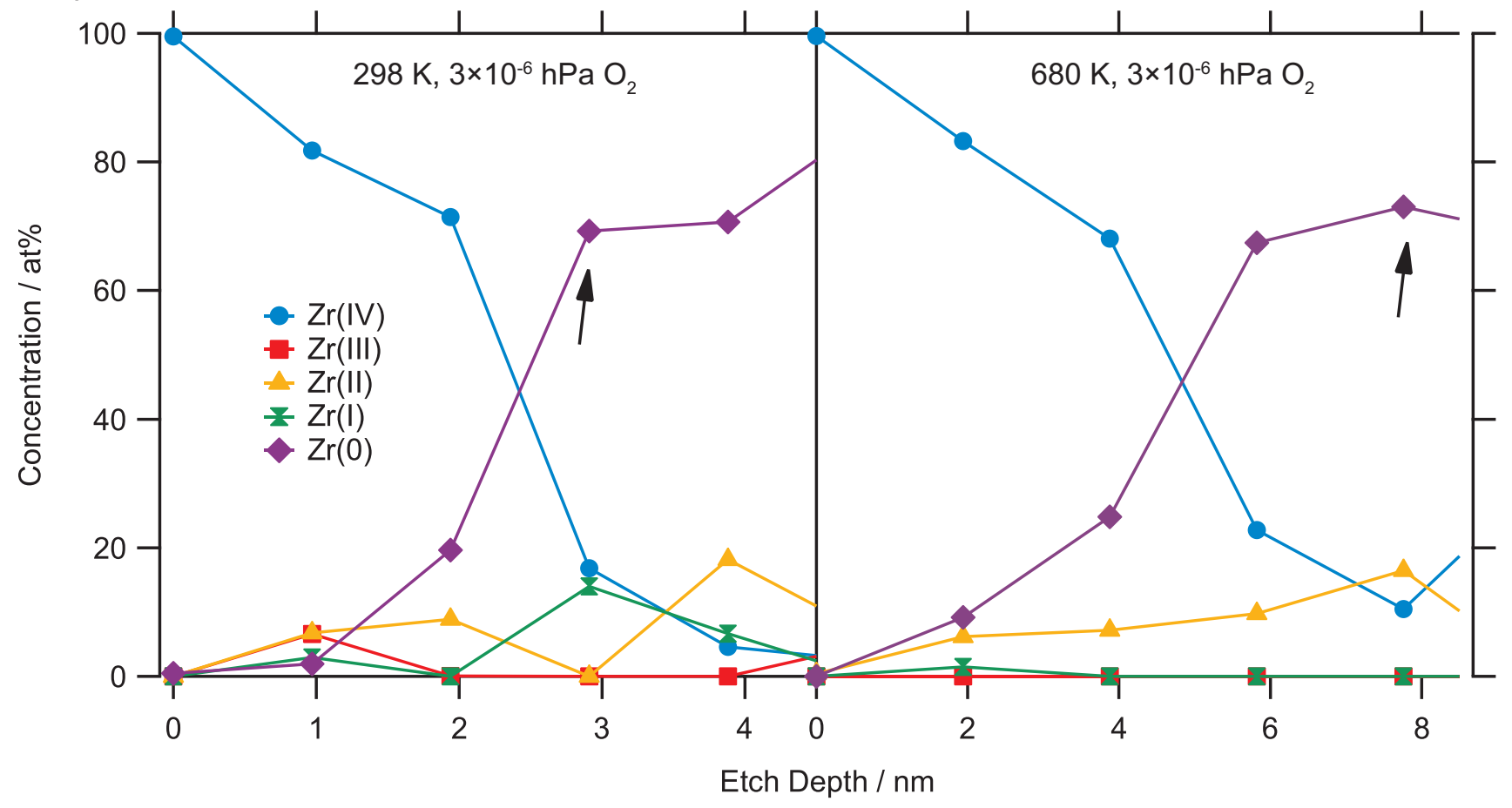

b)

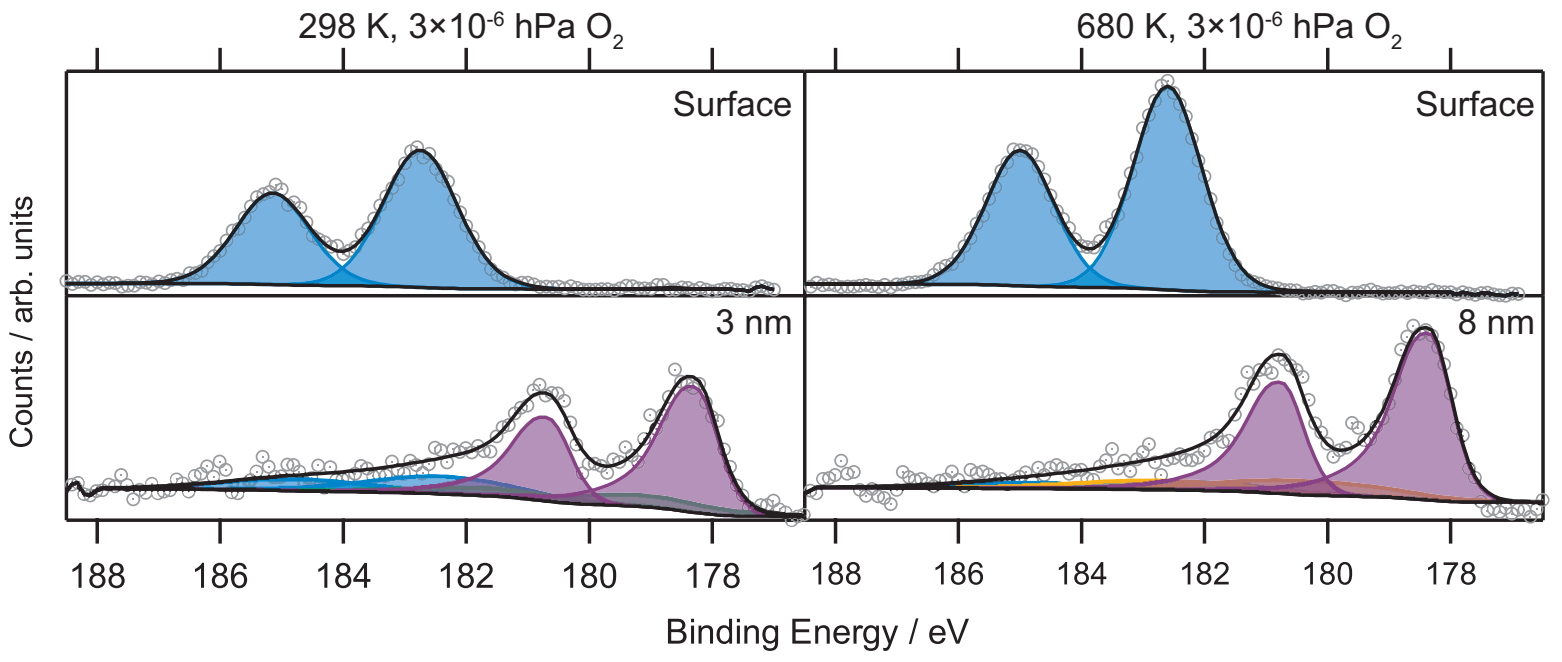

Figure 6: a) Chemical state profiles on Si substrates at different deposition temperatures. b) Exemplary XP spectra at the surface and the point marked by an arrow in a), analogous to Figure 5.

The depositions were also carried out on Si substrates, which were kept at different temperatures, using $3 \times 10^{-6} \mathrm{hPa}$ of $\mathrm{O}_{2}$ in $2 \times 10^{-4} \mathrm{hPa}$ Ar. Two examples of the resulting depth profiles are shown in Figure 6a) Both the specimen deposited at room temperature as well as the one prepared at $680 \mathrm{~K}$ show drastically 
different oxidation states, with the amount of $\operatorname{Zr}(\mathrm{IV})$ decreasing rapidly below the $20 \%$ mark. This decrease is accompanied by the rise of metallic zirconium in both cases. In fact, these profiles do not exhibit any discernible influence of the deposition temperature, with both looking very similar. The spectra in Figure 6b) reveal the difference to the films on the $\mathrm{Cu}$ substrates as, while they are fully oxidized at the surface, the $\operatorname{Zr}(0)$ signal is significantly more pronounced than for the other specimens (making up more than $70 \%$ of the total Zr signal), despite the same (relatively high) oxygen partial pressure being used for the depositions on $\mathrm{Cu}$ and $\mathrm{Si}$.

According to condensed phase thermodynamic data, $\mathrm{ZrO}_{2}$ is more stable than $\mathrm{SiO}_{2}$ at all temperatures, [70] which excludes a redox reaction between the two species as a possible mechanism leading to the observed electronic states. Even though more reduced zirconia species are expected to be less stable than fully oxidized $\mathrm{ZrO}_{2}$, the fact that metallic $\mathrm{Zr}$ is also found for the substrate deposited at room temperature, where the diffusion in a solid medium is very low. Thus, such a solid state reaction is unlikely to occur with the same rate at room temperature as at $680 \mathrm{~K}$. The absence of a temperature dependence of the chemical states and the different oxidation states of $\mathrm{Zr}$ on different substrates at the same oxygen partial pressures suggest that the substrates themselves seem to be involved in the reaction between $\mathrm{Zr}$ and O. A possible explanation of these effects is that the $\mathrm{Zr}$ is not primarily oxidized at the target or in the gas phase after being ejected from the target, but rather at the surface of the substrate. Hence, the sputtered Zr species are strongly reduced and, to a certain degree, even metallic when they arrive at the substrate, and are subsequently oxidized by the adsorbed oxygen present on the substrate. This is in good agreement with data on the sticking coefficient, which is larger on $\mathrm{Cu}$ than on $\mathrm{Si}$ by a factor of 10.[71, 72] Thus, copper, where $\mathrm{O}_{2}$ adsorption is more favorable, can act as an "oxygen pump", resulting in an in situ annealing process on the growing thin film, leading to higher oxidations states. In contrast, the amount of oxygen on the surface of the silicon wafer is negligibly small, which is why the zirconia remains strongly substoichiometric/metallic. Due to the island/cluster growth that was inferred from the thickness calibration in Figure 4 for small deposited amounts, the surface of the substrate is exposed during the early stages of the sputter-deposition. Thus, the increased interface between the copper and the substoichiometric zirconia clusters causes an increased oxidation of the zirconium species. This mechanism is also corroborated by data from the variant of our source that was adapted by Lackner et al., where the sputter-deposition in $1 \times 10^{-6} \mathrm{hPa}$ of $\mathrm{O}_{2}$ onto a $\mathrm{Rh}(111)$ single crystal, for which the sticking coefficient of oxygen is very close to $1,[73]$ resulted in a fully oxidized $\mathrm{ZrO}_{2}$ film.[60]

The proposed mechanism involving the reaction with adsorbed oxygen species on the substrates apparently contradicts other previously reported suggestions such as that by Yoshitake et al.,[74] who were able to describe their reactive sputtering process (using an ion beam) by reactions solely occurring at the surface of their zirconium target. In our case, these reactions do not seem to take place, which could be ascribed to the already mentioned high temperatures the target experiences due to radiative heating from the filament 
that is in close proximity. This could reduce the sticking coefficient of oxygen on the surface, essentially causing ballistic reflections of all impinging oxygen molecules instead of adsorption reactions. It is possible, however, that their data could also be described by a quantitative model of the reactions occurring at the substrate surfaces. In order to set up such a model thoroughly, more experiments are required in the future.

\subsection{Proposal for a High Deposition Rate Sputter Source}

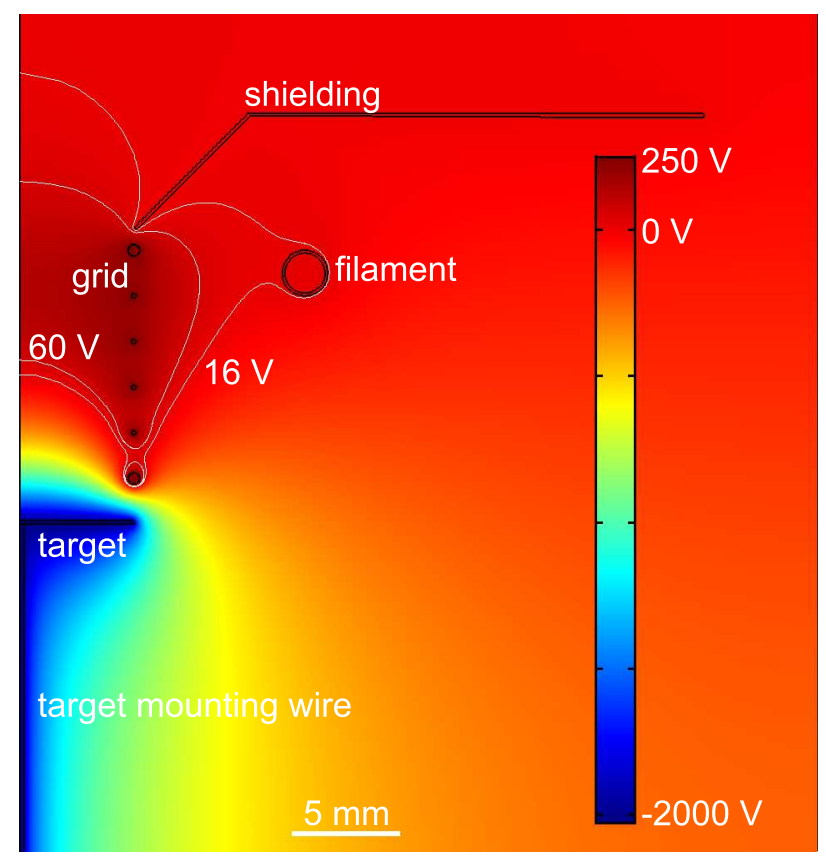

Figure 7: Electric potentials of an alternative sputter source geometry. A cylindrical grid leads to an increased volume where the electron impact ionization of Ar can take place.

One of the advantages of the direct current ion beam sputter source used in this work to deposit the substoichiometric zirconia thin films is its modularity and flexibility. Thus, different components, such as the shielding or the grid, can be exchanged easily. Depending on the requirement, different configurations are possible. For instance, as shown in Figure 7, replacing the conical grid by a cylindrical one increases the volume, inside of which the electron impact ionization of argon is possible - even though all parameters, such as the voltages applied to the different elements, are the same. This leads to a significantly higher number of $\mathrm{Ar}^{+}$formed, which subsequently increases the deposition rate. However, the potential diagram also reveals that there is a negative gradient of the potential toward the substrate within the region of Ar ionization. Consequently, some of the argon ions will be accelerated toward the substrate, which is also a problem with the two-grid version reported by Lackner et al.[60] Thus, Ar ions with kinetic energies of up to $250 \mathrm{eV}$ can bombard the substrate and roughen up the surface of the thin film by simultaneous sputtering as it is deposited. 

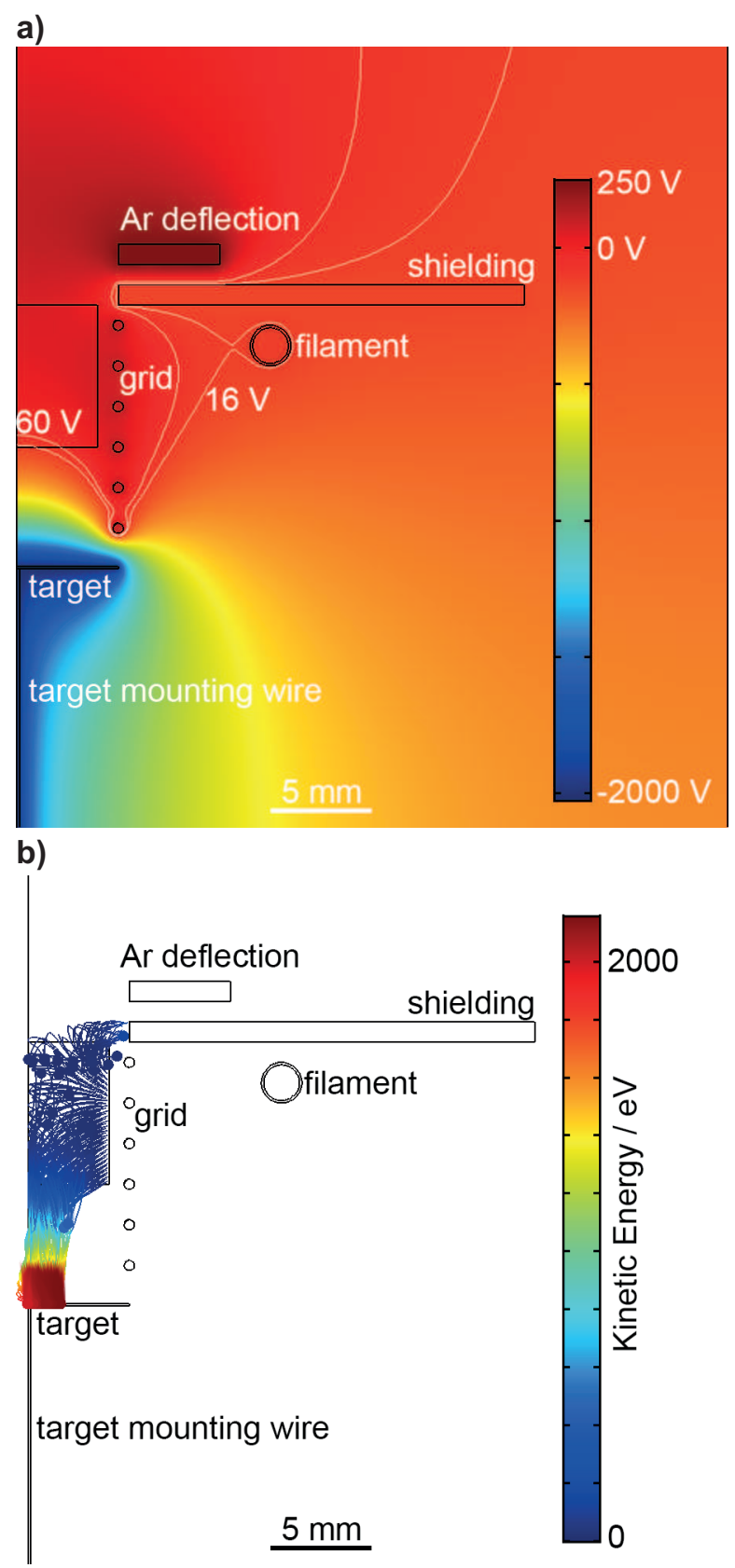

Figure 8: a) Electric potentials of the same source as in Figure 7, but with a slightly different shielding that includes a positively biased Ar deflection aperture to prevent $\mathrm{Ar}^{+}$from hitting the substrate. b) The ion trajectories prove the function of the argon deflection potential.

This effect, however, can be prevented by adding an $\mathrm{Ar}^{+}$-blocking potential above the shielding, which hinders the Ar ions from leaving the sputter source head. An example geometry solving the problem of ions hitting the substrate is shown in Figure 8a). For the sake of simplicity, a slightly different, planar, shielding is used that, again is kept at ground potential. Just above this shielding, there is an annular aperture biased 
at a voltage that is even more positive than the potential of the grid (in this case, the aperture is at $300 \mathrm{~V}$ ). This causes a potential barrier across the whole orifice of the source head, letting sputtered particles through, but blocking $\mathrm{Ar}^{+}$. Prove of this behavior is displayed in Figure 8b) in the form of $\mathrm{Ar}^{+}$trajectories. Here, the ionization volume approximating that obtained for the configuration in Figure 7 is used as the additional Ar-deflecting aperture does not influence the volume of the electron impact ionization significantly. Even though the iso-potential lines at 16 and $60 \mathrm{~V}$ in panel a) comprise a pronouncedly larger volume, these areas are inaccessible to the thermionic electrons emitted by the filament, rendering this approximation valid. The Ar paths show that, indeed, no Ar ions move toward the substrate (i.e. to the top in the graphic), with more than $75 \%$ hitting the target (and the rest being neutralized by the shielding, where no sputtering occurs as the $\mathrm{Ar}$ is slowed down to low energies by the potential caused by the deflection aperture). In contrast to the configuration used in this work (with the conical grid), not the whole grid is sputtered, but a circle of approximately half the diameter of the whole target. The target utilization could be improved by moving the target away from the grid.

\section{Conclusion}

We have demonstrated the applicability of an ion beam sputter source for reactive sputtering in oxygenor hydrogen-containing environments. We have shown that the drain current recorded at the target can be used as a figure of merit for the sputter rate and, subsequently, also the deposited film thickness. A systematic study of thin film thicknesses, measured using XPS depth profiling, as a function of the integrated drain current revealed a linear dependence between the two properties. The exact control of the deposited amount makes this source usable for a variety of surface science applications as, with the same source, the deposition of sub-monolayers is just as easily possible as the preparation of thicker films in the $100 \mathrm{~nm}$ range. Furthermore, based on FEM calculations, more configurations for different applications were presented.

The influence of the sputter gas on the oxidation states of the thin films deposited on copper foils was investigated by sputtering at different oxygen and hydrogen partial pressures. While all samples were oxidized at the surface, which was ascribed to the reaction with air during the transfer to the photoelectron spectrometer, distinct differences were observed in the bulk of the films: the lower the $p\left(\mathrm{O}_{2}\right)$, the lower the amount of $\mathrm{Zr}(\mathrm{IV})$, with increasing suboxidic species. Using $3 \times 10^{-6} \mathrm{hPa}$ of hydrogen, mixed into $2 \times 10^{-4} \mathrm{hPa} \mathrm{Ar}$, small amounts of metallic $\mathrm{Zr}$ could identified in the resulting specimens. The concentration of $\operatorname{Zr}(0)$ was significantly higher for the thin films deposited onto Si wafer substrates, hinting at a reaction mechanism where the deposited, strongly reduced $\mathrm{Zr}$ species react with oxygen that is adsorbed on the substrate, in contrast to the usually reported mechanisms for reactive sputtering that take place on the target surface.[74] Since the sticking coefficient for $\mathrm{O}_{2}$ is significantly larger on $\mathrm{Cu}$ than on $\mathrm{Si}$, this could explain the differences in the oxidation states on both substrates, which is not possible by a reaction that 
occurs on the target itself. Further experiments and DFT calculations are needed to formulate a theoretical model in order to describe this mechanism quantitatively.

The thin films prepared in this work, with the ability to tune their degree of oxidation by variation of the $\mathrm{O}_{2}$ partial pressure during the deposition, are ideal model systems for different applications, including optical devices and catalysis. Here, the UHV-compatibility of our sputter source becomes important as this allows the characterization of the samples without contact to air (i.e. without the fully oxidized surface region).

\section{Acknowledgments}

This work was financially supported by the Austrian Science Fund (FWF) via grant F4503-N16 (SFB "Functional Oxide Surfaces and Interfaces", FOXSI) and has been performed within the framework of the Forschungsplattform Materials and Nanoscience at the University of Innsbruck.

\section{References}

\section{References}

[1] Y. Han, J. Zhu, Surface Science Studies on the Zirconia-Based Model Catalysts, Top. Catal. 56 (15-17) (2013) $1525-1541$. doi:10.1007/s11244-013-0156-5.

[2] M. Copel, M. Gribelyuk, E. Gusev, Structure and stability of ultrathin zirconium oxide layers on Si(001), Appl. Phys. Lett. 76 (4) (2000) 436-438. doi:10.1063/1.125779.

[3] J. Wang, L. Zhao, N. H.Luu, D. Wang, H. Nakashima, Structural and electrical properties of Zr oxide film for high$\mathrm{k}$ gate dielectrics by using electron cyclotron resonance plasma sputtering, Appl. Phys. A 80 (8) (2005) 1781-1787. doi:10.1007/s00339-003-2483-z.

[4] G. D. Wilk, R. M. Wallace, J. M. Anthony, High- $\kappa$ gate dielectrics: Current status and materials properties considerations, J. Appl. Phys. 89 (10) (2001) 5243-5275. doi:10.1063/1.1361065.

[5] J. J. Yu, I. W. Boyd, $\mathrm{ZrO}_{2}$ films deposited by photo-CVD at low temperatures, Appl. Phys. A: Mater. Sci. Process. 75 (4) (2002) 489-491. doi:10.1007/s003390201294.

[6] L. Xikun, L. Jing, Q. Like, C. Tong, Q. Guanming, S. Yanbin, Composition, Characteristics and Development of Advanced Ceramic Cutting Tools, J. Rare Earths 25 (2007) 287-294. doi:10.1016/S1002-0721(07)60490-6.

[7] G.-L. Tan, X.-J. Wu, Electronic conductivity of a $\mathrm{ZrO}_{2}$ thin film as an oxygen sensor, Thin Solid Films 330 (2) (1998) 59-61. doi:10.1016/S0040-6090(98)00759-7.

[8] H. Hsu, S. Yen, Evaluation of metal ion release and corrosion resistance of $\mathrm{ZrO}_{2}$ thin coatings on the dental Co-Cr alloys, Dent. Mater. 14 (5) (1998) 339-346. doi:10.1016/S0109-5641(99)00002-0.

[9] G. Soon, B. Pingguan-Murphy, K. W. Lai, S. A. Akbar, Review of zirconia-based bioceramic: Surface modification and cellular response, Ceram. Int. 42 (11) (2016) 12543-12555. doi:10.1016/j.ceramint.2016.05.077.

[10] J. Wang, H. P. Li, R. Stevens, Hafnia and hafnia-toughened ceramics, J. Mater. Sci. 27 (20) (1992) 5397-5430. doi:10.1007/BF00541601.

[11] J. LI VAGE, K. DOI, C. MAZIERES, Nature and Thermal Evolution of Amorphous Hvdrated Zirconium Oxide, J. Am. Ceram. Soc. 51 (6) (1968) 349-353. doi:10.1111/j.1151-2916.1968.tb15952.x. 
[12] T. H. Etsell, S. N. Flengas, Electrical properties of solid oxide electrolytes, Chem. Rev. 70 (3) (1970) 339-376. doi:10.1021/cr60265a003.

[13] Steele, Brian C. H., A. Heinzel, Materials for fuel-cell technologies, Nature 414 (6861) (2001) $345-352$. doi:10.1038/35104620.

[14] N. Miura, T. Sato, S. A. Anggraini, H. Ikeda, S. Zhuiykov, A review of mixed-potential type zirconia-based gas sensors, Ionics 20 (7) (2014) 901-925. doi:10.1007/s11581-014-1140-1.

[15] P. Yashar, J. Rechner, M. S. Wong, W. D. Sproul, S. A. Barnett, High-rate reactive sputtering of yttria-stabilized zirconia using pulsed d.c. power, Surf. Coat. Technol. 94-95 (1997) 333-338. doi:10.1016/S0257-8972(97)00270-3.

[16] R. Vaßen, Thermal Barrier Coatings, in: R. Riedel, I.-W. Chen (Eds.), Ceramics Science and Technology, Wiley-VCH Verlag GmbH \& Co. KGaA, Weinheim, Germany, 2013, pp. 95-115. doi:10.1002/9783527631940.ch52.

[17] P. Amézaga-Madrid, A. Hurtado-Macías, W. Antúnez-Flores, F. Estrada-Ortiz, P. Pizá-Ruiz, M. Miki-Yoshida, Synthesis, microstructural, optical and mechanical properties of yttria stabilized zirconia thin films, J. Alloys Compd. 536 (2012) S412-S417. doi:10.1016/j.jallcom.2011.11.111.

[18] N. Köpfle, L. Mayr, P. Lackner, M. Schmid, D. Schmidmair, T. Götsch, S. Penner, B. Kloetzer, Zirconium-Palladium Interactions during Dry Reforming of Methane, ECS Trans. 78 (1) (2017) 2419-2430. doi:10.1149/07801.2419ecst.

[19] N. Köpfle, L. Mayr, D. Schmidmair, J. Bernardi, A. Knop-Gericke, M. Hävecker, B. Klötzer, S. Penner, A Comparative Discussion of the Catalytic Activity and $\mathrm{CO}_{2}$-Selectivity of $\mathrm{Cu}-\mathrm{Zr}$ and $\mathrm{Pd}-\mathrm{Zr}$ (Intermetallic) Compounds in Methanol Steam Reforming, Catalysts 7 (12) (2017) 53. doi:10.3390/catal7020053.

[20] J. I. J. Choi, W. Mayr-Schmölzer, F. Mittendorfer, J. Redinger, U. Diebold, M. Schmid, The growth of ultra-thin zirconia films on $\operatorname{Pd}_{3} \operatorname{Zr}(000$ 1), J. Phys. Condens. Matter 26 (22) (2014) 225003. doi:10.1088/0953-8984/26/22/225003.

[21] J. I. J. Choi, W. Mayr-Schmölzer, I. Valenti, P. Luches, F. Mittendorfer, J. Redinger, U. Diebold, M. Schmid, Metal Adatoms and Clusters on Ultrathin Zirconia Films, J. Phys. Chem. C 120 (18) (2016) 9920-9932. doi:10.1021/acs.jpcc.6b03061.

[22] H. Li, J.-I. J. Choi, W. Mayr-Schmölzer, C. Weilach, C. Rameshan, F. Mittendorfer, J. Redinger, M. Schmid, G. Rupprechter, Growth of an Ultrathin Zirconia Film on $\mathrm{Pt}_{3} \mathrm{Zr}$ Examined by High-Resolution X-ray Photoelectron Spectroscopy, Temperature-Programmed Desorption, Scanning Tunneling Microscopy, and Density Functional Theory, J. Phys. Chem. C 119 (5) (2015) 2462-2470. doi:10.1021/jp5100846.

[23] D. D. Kumar, N. Kumar, K. Panda, A. M. Kamalan Kirubaharan, P. Kuppusami, Tribochemistry of contact interfaces of nanocrystalline molybdenum carbide films, Appl. Surf. Sci. 447 (2018) 677-686. doi:10.1016/j.apsusc.2018.04.042.

[24] V. Dev, Lithium intercalation studies in cubic titanium carbide thin films, Appl. Surf. Sci.doi:10.1016/j.apsusc.2018.01.284.

[25] S. Du, K. Zhang, M. Wen, Y. Qin, R. Li, H. Jin, X. Bao, P. Ren, W. Zheng, Optimizing the tribological behavior of tantalum carbide coating for the bearing in total hip joint replacement, Vacuum 150 (2018) 222-231. doi:10.1016/j.vacuum.2018.01.050.

[26] K. Kefif, Y. Bouizem, A. Belfedal, J. D. Sib, D. Benlakehal, L. Chahed, Hydrogen related crystallization in silicon carbide thin films, Optik 154 (2018) 459-466. doi:10.1016/j.ijleo.2017.10.083.

[27] Y. He, J. Zhang, B. Luo, K. Li, L. Chen, W. Li, J. Luo, W. Wu, Effect of substrate temperature on the microstructure and properties of $\mathrm{Be}_{2} \mathrm{C}$ films: Aim to advance its applications as ICF ablator, J. Alloys Compd. 728 (2017) 71-77. doi:10.1016/j.jallcom.2017.08.185.

[28] Y.-S. Jhong, C.-W. Huang, S.-J. Lin, Effects of $\mathrm{CH}_{4}$ flow ratio on the structure and properties of reactively sputtered (CrNbSiTiZr)C $C_{x}$ coatings, Mater. Chem. Phys. 210 (2018) 348-352. doi:10.1016/j.matchemphys.2017.08.002.

[29] D. D. Kumar, N. Kumar, S. Kalaiselvam, R. Radhika, A. Maximus Rabel, R. Jayavel, Tribo-mechanical properties of reactive magnetron sputtered transition metal carbide coatings, Tribol. Int. 114 (2017) $234-244$. doi:10.1016/j.triboint.2017.04.031. 
[30] H. Du, L. Wang, M. Young, H. Zhao, J. Xiong, W. Wan, Structure and properties of lanthanum doped AlCrN coatings, Surf. Coat. Technol. 337 (2018) 439-446. doi:10.1016/j.surfcoat.2018.01.060.

[31] K. Johansson, E. Lewin, Influence of oxygen content on structure and material properties of reactively sputtered Al-Ge-O-N thin films, J. Alloys Compd. 738 (2018) 515-527. doi:10.1016/j.jallcom.2017.12.185.

[32] A. Schütze, K. Bewilogua, H. Lüthje, S. Kouptsidis, Preparation of cubic boron nitride films by reactive sputtering from a boron carbide target, Diamond Relat. Mater. 5 (10) (1996) 1130-1135. doi:10.1016/0925-9635(96)00530-4.

[33] J. Rezek, J. Vlček, J. Houška, J. Čapek, P. Baroch, Enhancement of the deposition rate in reactive mid-frequency ac magnetron sputtering of hard and optically transparent $\mathrm{ZrO}_{2}$ films, Surf. Coat. Technol. 336 (2018) 54-60. doi:10.1016/j.surfcoat.2017.09.015.

[34] A. Belosludtsev, J. Vlček, J. Houška, R. Čerstvý, Reactive high-power impulse magnetron sputtering of $\mathrm{ZrO}_{2}$ films with gradient $\mathrm{ZrO}_{\mathrm{x}}$ interlayers on pretreated steel substrates, J. Vac. Sci. Technol. A 35 (3) (2017) 031503. doi:10.1116/1.4978037.

[35] B. Coskun, T. Asar, U. Akgul, K. Yildiz, Y. Atici, Investigation of structural and electrical properties of Zirconium dioxide thin films deposited by reactive RF sputtering technique, Ferroelectrics 502 (1) (2016) 147-158. doi:10.1080/00150193.2016.1235453.

[36] P. Gao, L. Meng, M. dos Santos, V. Teixeira, M. Andritschky, Characterisation of $\mathrm{ZrO}_{2}$ films prepared by rf reactive sputtering at different $\mathrm{O}_{2}$ concentrations in the sputtering gases, Vacuum 56 (2) (2000) 143-148. doi:10.1016/S0042207X(99)00199-2.

[37] R.-s. Han, L.-q. Qi, L.-h. Liu, Q. Xu, G.-X. Guo, H.-y. Sun, Microstructures and room temperature ferromagnetism of ordered porous $\mathrm{ZrO}_{2}$ thin films sputter deposited onto porous anodic alumina substrates, J. Magn. Magn. Mater. 428 (2017) 99-104. doi:10.1016/j.jmmm.2016.12.034.

[38] T. Kozák, J. Vlček, A parametric model for reactive high-power impulse magnetron sputtering of films, J. Phys. D: Appl. Phys. 49 (5) (2016) 055202. doi:10.1088/0022-3727/49/5/055202.

[39] T. Kozák, J. Vlček, Dynamics of processes during the deposition of $\mathrm{ZrO}_{2}$ films by controlled reactive high-power impulse magnetron sputtering: A modelling study, J. Appl. Phys. 122 (4) (2017) 043304. doi:10.1063/1.4996186.

[40] J. Čyviene, M. Laurikaitis, J. Dudonis, Effect of magnetron target temperature on deposition rate and structure of $\mathrm{Zr}-\mathrm{ZrO} 2$ thin films, Lith. J. Phys. 44 (5) (2004) 353-358.

[41] K. V. L. V. Narayanachari, H. Chandrasekar, A. Banerjee, K. B. R. Varma, R. Ranjan, N. Bhat, S. Raghavan, Growth stress induced tunability of dielectric permittivity in thin films, J. Appl. Phys. 119 (1) (2016) 014106. doi:10.1063/1.4939466.

[42] A. D. Pajdarová, J. Vlček, J. Rezek, Optical emission spectroscopy during the deposition of zirconium dioxide films by controlled reactive high-power impulse magnetron sputtering, J. Appl. Phys. 121 (17) (2017) 171908. doi:10.1063/1.4977822.

[43] M. Velumani, S. R. Meher, L. Balakrishnan, R. Sivacoumar, Z. C. Alex, $\mathrm{ZrO}_{2}-\mathrm{ZnO}$ composite thin films for humidity sensing, AIP Conference Proceedings 1731 (2016) 080032. doi:10.1063/1.4947910.

[44] J. Vlček, J. Rezek, J. Houška, T. Kozák, J. Kohout, Benefits of the controlled reactive high-power impulse magnetron sputtering of stoichiometric $\mathrm{ZrO}_{2}$ films, Vacuum 114 (2015) 131-141. doi:10.1016/j.vacuum.2014.12.004.

[45] M. Verma, V. Kumar, A. Katoch, Synthesis of $\mathrm{ZrO}_{2}$ nanoparticles using reactive magnetron sputtering and their structural, morphological and thermal studies, Mater. Chem. Phys. 212 (2018) 268-273. doi:10.1016/j.matchemphys.2018.03.049.

[46] S. A. K. M. Faruque, R. P. Giri, S. Chakraborty, Effect of $\mathrm{N}_{2} \mathrm{O}$ ratio on the crystallization temperature of $\mathrm{ZrO}_{2}$ film deposited on $\mathrm{Si}$ by reactive sputtering in $\mathrm{Ar} / \mathrm{O}_{2} / \mathrm{N}_{2} \mathrm{O}$ plasma, Mater. Res. Express 3 (11) (2016) 116406. doi:10.1088/2053$1591 / 3 / 11 / 116406$.

[47] A. A. Solovyev, A. M. Lebedynskiy, A. V. Shipilova, I. V. Ionov, E. A. Smolyanskiy, A. L. Lauk, G. E. Remnev, Deposition of nickel oxide-yttria stabilized zirconia thin films by reactive magnetron sputtering, Int. J. Hydrogen Energydoi:10.1016/j.ijhydene.2018.01.076.

[48] A. A. Solovyev, A. V. Shipilova, I. V. Ionov, A. N. Kovalchuk, S. V. Rabotkin, V. O. Oskirko, Magnetron-Sputtered YSZ 
and CGO Electrolytes for SOFC, J. Electron. Mater. 45 (8) (2016) 3921-3928. doi:10.1007/s11664-016-4462-0.

[49] J. S. Lamas, W. P. Leroy, D. Depla, The fictional transition of the preferential orientation of yttria-stabilized zirconia thin films, Thin Solid Films 525 (2012) 6-12. doi:10.1016/j.tsf.2012.10.061.

[50] J. Yan, Y. Kuo, J. Lu, Zirconium-Doped Hafnium Oxide High-k Dielectrics with Subnanometer Equivalent Oxide Thickness by Reactive Sputtering, Electrochem. Solid-State Lett. 10 (7) (2007) H199. doi:10.1149/1.2730720.

[51] L. Landälv, J. Lu, S. Spitz, H. Leiste, S. Ulrich, M. P. Johansson-Jõesaar, M. Ahlgren, E. Göthelid, B. Alling, L. Hultman, M. Stüber, P. Eklund, Structural evolution in reactive RF magnetron sputtered $(\mathrm{Cr}, \mathrm{Zr}){ }_{2} \mathrm{O}_{3}$ coatings during annealing, Acta Mater. 131 (2017) 543-552. doi:10.1016/j.actamat.2017.03.063.

[52] Š. Zuzjaková, P. Zeman, S. Haviar, R. Čerstvý, J. Houška, J. Rezek, J. Vlček, Thermal stability of structure, microstructure and enhanced properties of $\mathrm{Zr}-\mathrm{Ta}-\mathrm{O}$ films with a low and high Ta content, Surf. Coat. Technol. 335 (2018) $95-103$. doi:10.1016/j.surfcoat.2017.12.026.

[53] Q. N. Meng, M. Wen, C. Q. Qu, C. Q. Hu, W. T. Zheng, Preferred orientation, phase transition and hardness for sputtered zirconium nitride films grown at different substrate biases, Surf. Coat. Technol. 205 (8-9) (2011) 2865-2870. doi:10.1016/j.surfcoat.2010.10.060.

[54] E. Grigore, C. Ruset, X. Li, H. Dong, Zirconium carbonitride films deposited by combined magnetron sputtering and ion implantation (CMSII), Surf. Coat. Technol. 204 (12-13) (2010) 1889-1892. doi:10.1016/j.surfcoat.2009.11.012.

[55] T. Götsch, W. Wallisch, M. Stöger-Pollach, B. Klötzer, S. Penner, From zirconia to yttria: Sampling the YSZ phase diagram using sputter-deposited thin films, AIP Adv. 6 (2) (2016) 25119. doi:10.1063/1.4942818.

[56] L. Mayr, N. Köpfle, A. Auer, B. Klötzer, S. Penner, An (ultra) high-vacuum compatible sputter source for oxide thin film growth, Rev. Sci. Instrum. 84 (9) (2013) 94103. doi:10.1063/1.4821148.

[57] T. Götsch, L. Mayr, M. Stöger-Pollach, B. Klötzer, S. Penner, Preparation and characterization of epitaxially grown unsupported yttria-stabilized zirconia (YSZ) thin films, Appl. Surf. Sci. 331 (2015) 427-436. doi:10.1016/j.apsusc.2015.01.068.

[58] T. Götsch, E. Bertel, A. Menzel, M. Stöger-Pollach, S. Penner, Spectroscopic investigation of the electronic structure of yttria-stabilized zirconia, Phys. Rev. Materials 2 (3) (2018) 451. doi:10.1103/PhysRevMaterials.2.035801.

[59] T. Götsch, D. Hauser, N. Köpfle, J. Bernardi, B. Klötzer, S. Penner, Complex Oxide Thin Films: Pyrochlore, Defect Fluorite and Perovskite Model Systems for Structural, Spectroscopic and Catalytic Studies, Appl. Surf. Sci. accepted.

[60] P. Lackner, J. I. J. Choi, U. Diebold, M. Schmid, Construction and evaluation of an ultrahigh-vacuum-compatible sputter deposition source, Rev. Sci. Instrum. 88 (10) (2017) 103904. doi:10.1063/1.4998700.

[61] Y. Nishino, A. R. Krauss, Yuping Lin, D. M. Gruen, Initial oxidation of zirconium and Zircaloy-2 with oxygen and water vapor at room temperature, J. Nucl. Mater. 228 (3) (1996) 346-353. doi:10.1016/0022-3115(95)00194-8.

[62] Thermo Fisher Scientific Inc., XPS Simplified - Zirconium, https://xpssimplified.com/elements/zirconium.php (2018).

[63] W. H. Gries, A Universal Predictive Equation for the Inelastic Mean Free Pathlengths of X-ray Photoelectrons and Auger Electrons, Surf. Interface Anal. 24 (1) (1996) 38-50. doi:10.1002/(SICI)1096-9918(199601)24:1<38::AID-SIA84>3.0.CO;2H.

[64] K. Bartschat, P. G. Burke, Electron impact ionisation of argon, J. Phys. B: At. Mol. Opt. Phys. 21 (17) (1988) $2969-2975$. doi:10.1088/0953-4075/21/17/010.

[65] K. Stephan, H. Helm, T. D. Märk, Mass spectrometric determination of partial electron impact ionization cross sections of He, Ne, Ar and Kr from threshold up to 180 eV, J. Chem. Phys. 73 (8) (1980) 3763-3778. doi:10.1063/1.440606.

[66] S. M. Younger, Distorted-wave electron-impact ionization cross sections for the argon isoelectronic sequence, Phys. Rev. A 26 (6) (1982) 3177-3186. doi:10.1103/PhysRevA.26.3177.

[67] A. Bogaerts, R. Gijbels, The ion- and atom-induced secondary electron emission yield: Numerical study for the effect of clean and dirty cathode surfaces, Plasma Sources Sci. Technol. 11 (1) (2002) 27-36. doi:10.1088/0963-0252/11/1/303.

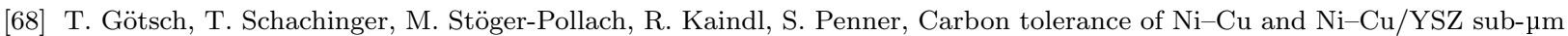


sized SOFC thin film model systems, Appl. Surf. Sci. 402 (2017) 1-11. doi:10.1016/j.apsusc.2017.01.076.

[69] I. Bespalov, M. Datler, S. Buhr, W. Drachsel, G. Rupprechter, Y. Suchorski, Initial stages of oxide formation on the Zr surface at low oxygen pressure: An in situ FIM and XPS study, Ultramicroscopy 159 Pt 2 (2015) $147-151$. doi:10.1016/j.ultramic.2015.02.016.

[70] M. W. Chase, Jr., NIST-JANAF Themochemical Tables, Fourth Edition, J. Phys. Chem. Ref. Data Monograph 9 (1998) $1-1951$.

[71] J. Eisinger, J. T. Law, Adsorption of Oxygen on Silicon, J. Chem. Phys. 30 (2) (1959) 410-412. doi:10.1063/1.1729965.

[72] A. Nesbitt, A. K. Lewin, A. Hodgson, Adsorption of oxygen on $\mathrm{Cu}(110)$, J. Phys.: Condens. Matter 3 (S) (1991) S71-S76. doi:10.1088/0953-8984/3/S/011.

[73] E. Schwarz, J. Lenz, H. Wohlgemuth, K. Christmann, The interaction of oxygen with a rhodium (110) surface, Vacuum 41 (1-3) (1990) 167-170. doi:10.1016/0042-207X(90)90299-E.

[74] M. Yoshitake, K. Takiguchi, Y. Suzuki, S. Ogawa, Effects of oxygen pressure in reactive ion beam sputter deposition of zirconium oxides, J. Vac. Sci. Technol. A 6 (4) (1988) 2326-2332. doi:10.1116/1.575584. 